\title{
Contrast Between English and Chinese Culturally-Loaded Words
}

\author{
LEI Chao \\ Zhoukou Normal University, Zhoukou, China
}

\begin{abstract}
Vocabulary in a language is influenced by and bears features of culture, so in languages, vocabulary has the greatest culture-loading capacity. This paper makes a contrastive study between English and Chinese culturally-loaded words, and tries to make clear how cultural disparities exist in English and Chinese vocabulary. Culturally-loaded words play a significant role in understanding the languages of different cultures, giving the readers insight into cultures. Learning and grasping the culturally-loaded words can promote the efficiency of vocabulary teaching and improve learners' competence in intercultural communication.
\end{abstract}

Keywords: contrast, culturally-loaded words, vocabulary teaching

\section{Introduction}

Every language possesses three cardinal elements: phonetic element, lexical element, and grammatical structure, of which lexis is the fundamental pillar that supports the huge system of a language (Bolinger, 2008, p. 226). The close relationship between language and culture is most readily seen in words. In fact, being the most active and elastic element of a language, vocabulary has the greatest culture-loading capacity. Vocabulary in a language is influenced by and bears features of culture. A number of words in English contain cultural elements, so scholars usually call them keywords (to society and culture), culturally bound or culturally conditioned words. No matter how they are differently termed, actually they refer to the same kind of words, namely, words that carry cultural meanings, mainly including nouns, adjectives, and numerals. HU Wen-zong (2012) points out that culturally-loaded words and expressions are loaded with specific national cultural information and indicate deep national culture (p. 108). Except for a part of core vocabulary in languages, many words and expressions are culturally-loaded. The cultural information loaded in these words and expressions are always barriers in appropriately understanding and using foreign language. This paper attempts to make a comparison between English and Chinese cultures, to make clear how cultural disparities exist in English and Chinese vocabulary. Learning and grasping the culturally-loaded words can promote the efficiency of vocabulary teaching and improve learners' competence in intercultural communication.

\section{Forms of Culturally-Loaded Words}

Culturally-loaded words usually appear in the following forms:

Nominal terms: Words under this category can find their referents in the physical world. Most of them are products, created by the people or generated in the soil of a particular culture. They range widely from utensils,

LEI Chao, M.A., Associate Professor, The Foreign Languages School, Zhoukou Normal University. 
implements, food, dresses, or costumes, to architectures, physical performances, art forms, or programs. Sandwich, salad, sonnet, chesterfield, Eton, Michaelmas, and so on in English, for instance, fall in this category.

Terms relating to social system: Every nation has its unique social system. For example, fair play not only shows a set of complex behavior norms absent in other countries but also passes on the norms that have long been believed in by the English to have met the need of society. In contrast, 仁, 义, 礼, 智, and the like that the Chinese held met the social demands in Chinese feudal society.

Idioms: Here, idioms are used in the broad sense, including colloquialisms, set phrases, proverbs, epigrams, slang expressions, and quotations. They are intimately linked to history, religious faiths, customs, and geographical surroundings of a given people and thus are culture-specific. Most of them have been well recorded in cultural works, and have been considered as an important component in the system of culturally-loaded words.

Symbolic terms: People always look forward to a happy, healthy, and peaceful life. In the aspect of morality, they admire the noble characters of persistence, purity, dauntlessness, etc. These concepts are deeply penetrated in their languages. For example, animal, plant, number, color, and other terms can easily lead to rich imaginations or associations. Such terms are usually considered as symbolic words.

Social terms: Terms of this kind mainly function on social occasions. They include the expressions of greetings, apology, humility and respect, responses to flattery and compliments, expressions of modesty, and taboos.

\section{Contrast Between English and Chinese Words From a Cultural Perspective}

Scholars studying semantics agree that words consist of two types of meaning: the denotative or designative meanings and the connotative or associative meanings. The designative meanings of words represent referents in the practical or linguistic world, while the connotative meanings represent the values and attitudes resulting from the use of words in discourses. The connotative meanings of a word may vary in different cultures (WANG, 2013, p. 223).

After making a comparison between Chinese and English words about their meanings, we can find some differences as follow:

(1) Similar in both denotation and connotation;

(2) Similar in denotation but partially overlapping in connotation;

(3) Similar in denotation but different in connotation;

(4) Culturally half-blank;

(5) Culturally blank capture imagination.

\section{Similar in Both Denotation and Connotation}

Words with similar referential meanings may arouse similar associations in different people. This is mainly due to the universality of human cognition or similar experiences people have in their life, or possibly the result of common understanding and evaluations people place on their customs, traditions, social norms, and religious beliefs. It makes possible communications between peoples and translations between different languages. For example, "the movable part at the end of the arm, including the fingers" is called 手 and hand respectively in Chinese and English. They also appear in expressions of similar structure with similar meanings, for example, $a$ good hand (好手), an old hand (老手). Both the English-speaking people and the Chinese regard the head as the 
dominant organ of the body. In both languages, the corresponding words carry similar associations. For instance, one of their associations is to stand for a leader or an important person: He is the head of our department (这是 我们系里的头).

Words of this kind are usually regarded as "culturally overlapped words”. The following list provides more illustrations: to lose heart (灰心); to break one's heart (伤心); heart-felt (衷心); heart to heart (心对心); heart and soul (全心全意); as light as a feather (轻如鸿毛); to add fuel to the flames (火上加油); cold words (冷言 冷语); castles in the air (空中楼阁); to gain one's laurel (勇夺桂冠); The fox is cunning (狐狸是狡猾的); Sheep are meek and obedient (绵羊是温顺的); and Our blood boils (我们热血沸腾).

\section{Similar in Denotation but Partially Overlapping in Connotation}

Some Chinese and English words have the same denotative meanings, but their connotative meanings are partially overlapping. For example, both the Chinese and the English view the owl as a bird of ill omen. The appearance of an owl heralds disaster: 夜猫子进宅, 无事不来 (An owl never enters one's house without bringing something bad). Interestingly, the owl is also a bird of wisdom in the eyes of the English. A smart guy is "owlish", or "as wise as an owl”. To send owls to Athens (to make an unnecessary effort) is an idiom derived from the Greek mythology in which the owl is the symbol of Athena, the goddess of wisdom. And in Chinese-English intercultural communications, kinship terms often present problems because satisfactory equivalents are not always available. Take uncle for example, in a specific context, its equivalent in Chinese may be 伯父 (father's elder brother), 叔父 (father's younger brother), 姑夫 (husband of father's sister), 舅父 (husband of mother's brother), or 姨夫 (husband of mother's sister). And the statement Linda's brother married Michael's sister is not easy to render into Chinese without further information about whether the brother is older or younger than Linda and whether the sister is Michael's elder or younger sister.

Some color words also pertain to this category.

For example, red is usually associated with celebrations and joyful occasions in the English-speaking countries as well as in China. So in English, we can find red-letter days, which means holidays such as Christmas, weekends, and other special days when people can get a holiday. Another examples are to roll out the red carpet for someone, which has the meaning of giving a lavish welcome, and to paint the town red, which means to celebrate heartily, to go out to drink and have a wonderful time. In Chinese, 红双喜 (literally, “double happiness in red") is the traditional symbol for an event of special joy, such as a wedding. Similarly, in 开门红 (literally, "open the door red"), the color red is symbolic of good fortune. Red is also the color associated with revolution and socialism. The English word red with a capital $\mathrm{R}$ is often used as a synonym for communists, violence, and blood in a derogatory sense. In Chinese, the word red symbolizes progress in a positive sense. For example, the Chinese phrase 一颗红心 (a red heart) means loyal to the Party, having socialist virtues, and 又红又专 actually means both socialist-minded and professionally qualified.

To most Chinese and English speaking people, white has certain similar connotations: purity and innocence. But in the Chinese culture, white also has derogatory connotations and symbolizes mourning. So at a traditional Chinese funeral, each person has a piece of white cloth on his or her head or has a white flower in front of his or her breast. What is more, white is also the symbol of reaction in the Chinese culture, as we can see in expressions like 白色恐怖, 白色据点, and 白区. 
In both English and Chinese cultures, there are various terms indicating that black is often given the meaning of “evil”, “false”, or “illegal”: Blacklist (黑名单), black market (黑市), black heart (黑心), a black sheep (害群之马), and a number of others. But in the expression 黑马, the word 黑 is associated with unexpectedness, just as in the English term a dark horse. In business English, in the black means running a business profitably, while in the red means running a business at a loss. They say so only because of the color of the ink used in keeping accounts—black ink is used to keep accounts for profitable business and red ink to keep accounts for business at a loss. The term in the red has been taken over in Chinese, as can be seen in the term 财政赤字 (DENG \& LIU, 2011, p. 60).

As for green, it symbolizes vigor, livingness, and environment-friendliness in both Chinese and English. Besides, in English, green is also often used to indicate someone's lack of experience or training knowledge in such expressions as a greenhorn. That refers to a person lacking experience, or a newcomer who is not familiar with local customs. Furthermore, English has the terms green with envy or green-eyed. The meaning of green in the two phrases is “jealous".

\section{Similar in Denotation but Different in Connotation}

Some Chinese and English words have the same denotative meanings, but quite different or even opposite connotative meanings. Words with similar referential meaning may evoke different associations in people from different cultural backgrounds. If one understands summer's day in Shakespeare's Shall I compare thee to a summer's day as a hot day, he or she is making a big mistake! As we all know, geographical environments are very unlike, and a summer's day means a cozy sunny day in Britain.

If an English native speaker says "That young man is a bear at mathematics", Chinese learners of English may feel surprised to know that this sentence simply means "He is good at mathematics". How can such “clumsy” animals (in Chinese: 笨熊) as bears be smart at anything? However, to the English-speaking people bears can be smart and endurable. It is natural that analogy is often made in English between bears and people who are endowed with high intelligence or remarkable power of endurance. In the English culture, the dog is often considered a cute creature and human beings' friendly companion. So, the word dog is mainly used with a commendatory sense, as in a lucky dog; to help a lame dog over a stile; to work like a dog; love me, love my dog. On the contrary, the Chinese often associate the word with derogatory connotations, as is reflected in expressions like 狗仗人势, 狼心狗肺, 狗急跳墙, and 狗头军师. Another frequently-quoted example is the legendary creature dragon. In the English culture, the dragon is often a symbol of evil, a fierce monster that should be destroyed. In oral English, the dragon is a metaphor of a fierce bad-tempered old woman. Therefore, many legends picture dragon-killing as a real test of courage and bravery of a hero. So 亚洲四小龙 is properly turned into not the four dragons of Asia but the four tigers of Asia. In sharp contrast to western ideas, the Chinese dragon is a sacred cultural symbol. Its awe-inspiring look and nobility portrayed in various forms have made frequent appearance in Chinese paintings, sculptures, architectures, and costumes. Chinese parents all 望子成龙 (to long for one's son to be successful), but its literal translation to expect one's son to become a dragon would sound quite ridiculous to the native English-speaking people. The dragon is valued so much that it becomes the token of China, and Chinese people proudly call themselves "the Descendants of the Dragon”. The dragon is honored as a godlike creature in the Chinese culture, with which the westerners are hard to sympathize. Examples alike are listed in the following table. 
Table 1

Culturally Half-blank Words in English and Chinese

\begin{tabular}{|c|c|c|}
\hline Referents & Cultural connotations in English and examples & Cultural connotations in Chinese and examples \\
\hline Chrysanthemum (菊花) & Only used in the funeral. & $\begin{array}{l}\text { A flower possessing the quality of being } \\
\text { extraordinary and refined. }\end{array}$ \\
\hline Bat (蝙蝠) & Ugly, sinister creature. & $\begin{array}{l}\text { A symbol of good fortune, well-being, and } \\
\text { happiness. }\end{array}$ \\
\hline Magpie (喜鹊) & A symbol of gossip. & A symbol of good fortune and happiness. \\
\hline Cattle (牛) & $\begin{array}{l}\text { Mostly negative attitude towards them, e.g., (1) a bull } \\
\text { in a china shop (someone crude); ( } 2 \text { ) like a bull at a } \\
\text { gate (rage, fierce); ( } 3 \text { ) throw the bull (talk nonsense); } \\
\text { and (4) bull-headed. }\end{array}$ & $\begin{array}{l}\text { Mostly positive attitude towards them, e.g., (1) 老 } \\
\text { 黄牛 (a hard-working person) and (2) 吃进去的 } \\
\text { 是草, 挤出来的是奶 (to demand little but to } \\
\text { contribute much). }\end{array}$ \\
\hline Yellow (黄) & $\begin{array}{l}\text { Contemptible, cowardly, suspicious, and jealous, e.g., } \\
\text { yellow-streak. }\end{array}$ & $\begin{array}{l}\text { (1) Nobility and royal family; (2) fortune: } \\
\text { represents the beauty of nature; (3) obscene, } \\
\text { pornography; and (4) unhealthy. }\end{array}$ \\
\hline Blue (蓝) & $\begin{array}{l}\text { (1) Obscene, pornography; (2) depressing, unhappy, } \\
\text { e.g., Love is blue; and (3) high birth, descent from } \\
\text { nobility, e.g., blue blood. }\end{array}$ & Quiet, giving people a pleasant feeling. \\
\hline Liberalism (自由主义) & Positive in English. & Pejorative in Chinese. \\
\hline Ambitious (野心勃勃) & Positive to Americans. & Pejorative in Chinese. \\
\hline
\end{tabular}

\section{Culturally Half-blank}

Influenced by the traditional culture, a common word in one language has associated meaning, but not its counterparts in another language. The connotative meanings of certain words are just stated in either Chinese or English, not in both. For example, the word daffodil in English culture is a symbol of spring and happiness. In the poem I Wandered Lonely as a Cloud by William Wordsworth, it reflects the joyful feeling of the author (PU, 2014, p. 84). However, its Chinese equivalent 水仙 has little such association and it is nothing but a kind of flower. Similarly, Chinese people are quite emotionally attached to certain plants, especially the bamboo. Since they are evergreen, immutable, and can stand up to the cold, bamboos have long been the key motif in Chinese poetry epitomizing 高风亮节 (exemplary conduct and nobility of character). In his poem Ode to the Bamboo, LI Cheng wrote, “常爱凌寒竹, 坚贞可喻人” (I worship the bamboo in fierce coldness, as a man should have that unyielding integrity). SHAO Ye described in his Nostalgia in Jingu Garden, “竹死不变节, 花落有余香” (The bamboo dies but never bends; flowers fall but their fragrance lingers). Due to these noble qualities they represent, many Chinese painters favor bamboos. And in English people's eyes, tigress simply refers to a female tiger and has no other associations, whereas 母老虎 in Chinese always indicates a pungent female. No wonder whenever Chinese students read the word and they cannot help laughing. ZHU Guang-qian, a noted Chinese scholar once pointed out pithily that words like shepherd, sea, castle, and nightingale carry rich lexical associations to the British and the same are words like 风, 花, 月, 江, 梅, 隐逸, and 阴阳 in Chinese (WANG, 2010, p. 86).

Many numbers are endowed with various mystique and have become symbolic in different cultures. In some parts of China, 4 is regarded as inauspicious number. Since 4 sounds like the word 死 (die or death) in Chinese, people dislike having 4 as the end of car number or among the telephone number. Almost for the same reason, Chinese people appreciate the number of 8 , which is assonant with 发 (become rich or flourishing), and try to have it as the end number. In the English culture, most people take 13 and Friday as taboos because of Christian tales. From the above, we can see numbers were not cast blindly into the world. Some other examples of such words are as follows: 
Table 2

Culturally Blank Words in English and Chinese

\begin{tabular}{|c|c|c|}
\hline Referent & Cultural connotations in English and examples & Cultural connotations in Chinese and examples \\
\hline White elephant (白象) & Something of no practical use. & I \\
\hline Beaver (海狸) & People working hard, e.g., an eager beaver. & / \\
\hline Potato (土豆) & $\begin{array}{l}\text { A man, e.g., a couch potato, a big potato, and } a \\
\text { clean potato (a decent man). }\end{array}$ & / \\
\hline Cat (猫) & $\begin{array}{l}\text { (1) A symbol of ill-omen and (2) pejorative, e.g., } \\
\text { catlike, cat's paw, and cat in the pan. }\end{array}$ & / \\
\hline Coot (白骨顶水鸟) & Complete bald, e.g., as bald as a coot. & I \\
\hline Goat (山羊) & The symbol of a wicked and lascivious man. & l \\
\hline Chicken (鸡) & The symbol of a coward. & l \\
\hline Silkworm (蚕) & / & A symbol for a diligent person. \\
\hline Pine (松树) & / & $\begin{array}{l}\text { A symbol for longevity, sturdiness; often paired } \\
\text { with the pine. }\end{array}$ \\
\hline Crane (鹤) & / & $\begin{array}{l}\text { A symbol for longevity, sturdiness: often paired } \\
\text { with the crane. }\end{array}$ \\
\hline Mandarin duck (鹗莺) & / & An affectionate couple. \\
\hline Apricot (杏) & / & $\begin{array}{l}\text { The Apricot Forest is used to signify the medical } \\
\text { circle. }\end{array}$ \\
\hline Turtle or tortoise (乌龟) & / & A symbol for longevity; cuckold. \\
\hline Full moon (圆月) & / & Reunion of relatives. \\
\hline Lotus (莲) & / & $\begin{array}{l}\text { Comes out of the dirty mud, unsoiled; remains } \\
\text { undefiled in spite of general corruption, vice, etc. }\end{array}$ \\
\hline
\end{tabular}

\section{Culturally Blank}

This category refers to these words that exist only in a particular culture. Even if it is possible to find some replacements or seemingly similar equivalents for them, they cannot be understood without their culture backgrounds. That is to say, the concepts that exist in one culture have no complete equivalence in another. This phenomenon is called lexical gap or lexical zero. The causes of these gaps are the different life experiences or different viewpoints of people from different cultures. Civilizations provide both Chinese and English languages with an abundance of cultural words. Take for an example, the twin concepts of yin and yang are peculiar for the ancient Chinese in understanding the world dialectically. The terms denote two opposite but complementary forces, coming from the Chinese characters meaning "shady" and "sunny". The union of these two was believed to give birth to all the different things in the universe (HU, 2011, p. 58). Yin and yang contradict, interact, and transform from one to another so as to achieve balance and harmony. Chinese philosophers have further assumed the importance of balance between them as a way to ensure social and political harmony. Though they are highly appreciated and have exerted a great influence on Chinese people's worldviews and their modes of thinking, yin and yang, given detailed explanations, are still mysterious concepts for the Westerners. And the Chinese have a saying, 冬练三九, 夏练三伏, urging people to exercise and keep fit. What are the English equivalents for 三九 and 三伏? A young interpreter was heard to use three nine and three fu to a group of Canadians. Naturally, they were puzzled. The English language has no counterparts for these Chinese words. He could have just said that one should keep exercising during the hottest days in summer and do the same thing during the coldest weather in winter. Other examples are 四合院，飞檐，and 照壁 in architecture，旗袍，马褂，and 唐装 in clothing, and 科 举, 状元, and 秀才 in the feudal education. In contrast, English words like chapel, kilt, Eton, brunch, 
ombudsman, hippie, motel, splashdown, pudding, Bloody Mary, and baby boomers are found to be lexical zeroes in Chinese.

\section{Conclusion}

In Geoffrey Leech's (1997) viewpoints of semantics, though in theory conceptual meaning is often the most important factor in communication, in some cases the importance of it will be reduced to almost zero. This best illustrates why communication failures always occur despite the fact that most English learners have a larger vocabulary than the 3,000 high-frequency words, which are considered by Palmer, one of the initiators of the Direct Method, to have covered more than 90\% of words in an average English text (Palmer \& Hornby, 2003, p. 6). It follows that the non-conceptual meaning of English words should be necessarily included in vocabulary teaching. Therefore, for the purpose of truly mastering the meaning of English words, one must at the same time have a deep understanding of cultures of the English-speaking countries.

Culture in language learning is not an expendable fifth skill, tacked on, so to speak, to the teaching of speaking, listening, reading, and writing. It is always in the background, right from day one, ready to unsettle the good language learners, making evident the limitation of their hard-won communicative competence, challenging their ability to make sense of the world around them. (Kramsch, 2015, p. 38)

The difference, variability, and potential for conflict are characteristics of culture. It is not surprising that misunderstandings and breakdowns are often seen in cross-cultural communications, therefore, emphasis on cultural contents may shed revealing light on vocabulary teaching.

\section{References}

Bolinger, D. (2008). Aspects of language. New York: Brace and World.

DENG, M., \& LIU, R. Q. (2011). Language and culture in conflicts. Beijing: Foreign Language Teaching and Research Press.

HU, D. G. (2011). Culturally loaded words and English language teaching in intercultural communication. Modern Foreign Language, 4, 39-40.

HU, W. Z. (2012). Intercultural communication and English learning. Beijing: Beijing University Press.

Kramsch, C. (2015). Culture in language teaching. Oxford: Oxford University Press.

Leech, G. (1997). Semantics. New York: Penguin Books.

Palmer, H. E., \& Hornby, A. S. (2003). Thousand-word English. London: Harrap.

PU, X. H. (2014). Developing cultural understanding through foreign language study. Foreign Language and Teaching, 8, 16-19.

WANG, F. X. (2010). Intercultural communication in English. Shanghai: Shanghai Foreign Language Education Press.

WANG, R. P. (2013). An advanced course of English lexicology. Shanghai: Shanghai Foreign Language Education Press. 